\title{
Increasing Space and Influence through Community Organising and Citizen Monitoring: Experiences from the USA
}

\section{Andy Mott}

\section{Introduction}

In the USA, poor people have relatively little power. While they can vote and create organisations to represent their interests, their power is severely limited by the fact that they are a relatively small minority within an enormously wealthy country. In this most capitalist of nations, their status is further weakened because they are often seen as people who have "failed" to compete effectively in the economy and society. Furthermore, as most of America's poor families are people of colour, they also are marginalised on racial grounds.

In addition, America's low-income families suffer from where they are concentrated. The jurisdictions where they represent a majority of the voters: poor rural towns and counties, declining cities, are areas in which local taxes are insufficient to support good schools, good services and the job training and job creation which would open up new economic opportunities. It therefore is not enough for them to marshal sufficient power to influence local governments. They must also influence higher levels of government and major corporations, because only those institutions have the resources needed to improve poor communities and increase opportunities for low-income people. This presents a daunting challenge, as influencing those larger bodies requires organising on a state-wide and even a national basis, an extraordinary difficult feat for grassroots groups who are short of resources and often isolated from each other.

Poor people in the USA must therefore be highly organised and active to have any influence on the issues that matter most in their lives. They must build powerful mass-based organisations to represent their interests and become highly creative in developing sophisticated strategies to maximise their influence. They must take full advantage of the political space which is open to them ("their space") and work to expand it and make decision making more transparent and more democratic. ${ }^{1}$ They must also create new space of their own ("our space" or "popular space"), where they can organise people and build organisations which increase their power, capacity, sophistication and influence. In this article, I look at the strategies that poor people and the organisations that represent them are using to expand their influence and strengthen democracy in the tough political context they face in the USA.

\section{Background: Government action to expand and then reduce political space}

During the 1960s, a series of mass-based movements shook the USA and brought about significant changes for poor people. Starting with the civil rights movement among African-Americans, waves of protest by Mexican-Americans, poor people, young activists, women, anti-war protestors, environmentalists and others pressed the federal, state and local governments to be more open and accountable to people who had long been neglected.

These movements coincided with a period of relatively progressive national leadership under Presidents Kennedy and Johnson. The results included gains in power by poor people and people 
of colour, new social programmes addressing their needs and a number of reforms responding to the needs of women, people with disabilities, young people and others who had mobilised to influence federal policies.

That era created new political space through important reforms in federal policy. Most importantly, voting rights reforms enabled AfricanAmericans and other minorities to overcome the barriers which had blocked them from exercising their influence at the ballot box. This led to dramatic gains in the number of minorities elected to office in major cities and throughout the South and Southwest where discrimination had been particularly egregious.

Other reforms were also significant in opening up government, making it more transparent and increasing accountability. The federal Freedom of Information Act opened access to key documents and enabled citizens to obtain information which previously had been inaccessible. Several federal programmes were revamped to foster citizen participation in decision making, mandating that local and state governments hold public hearings, create citizen advisory committees and otherwise consult with key constituencies. For several major programmes, federal officials increased accountability from local and state governments by requiring that they submit detailed applications and performance reports regarding their use of federal funds. These detailed reports increased transparency of government decision making and enabled citizens to track how funds were being budgeted, how well those budgets responded to their community's priorities, what progress was being made on promised projects and whether there was full compliance with legal requirements. These safeguards were particularly important to poor people and minorities who faced many barriers as they tried to influence policies and spending patterns.

Special efforts were launched to involve government in helping strengthen the voice and influence of poor people on key issues. The government's 'war on poverty' stressed the 'maximum feasible participation of the poor' in setting priorities and designing and running programmes. Many hired under the VISTA programme (a domestic volunteers programme for young people) were assigned to organise and staff community groups which were tackling important and sometimes controversial, issues. Other programmes also provided poor people's organisations with staff and funding, enabling them to increase their activity and impact. It was a time when progressives at the national level helped poor people build power and take on controversial issues.

In addition, the federal government established a programme, which created local offices of Legal Services advocates, who provided extraordinarily important legal backup for low-income people and their organisations. These attorneys played a key role in ensuring that poor people and minorities had the representation they needed to assert their rights. Over the last three decades they have brought many class actions and won significant changes in policies on welfare, housing, employment and a host of issues. Their help has often been crucial to forcing government agencies to abide by the law, including recognising the rights of tenants, minorities, or other protected groups to participate and assert their views as government decisions are made.

These federal reforms created new political space for low-income people, minorities and other disadvantaged groups to influence decisions by government agencies and private sector institutions. This grassroots/federal alliance was the key strategy for pursuing reforms and increasing the influence of disadvantaged people in the 1960s and it still is important today.

However, since the election of President Nixon in 1968, waves of conservative domination of the federal government have weakened the measures taken in the 1960s to create political space and increase the influence of disadvantaged people.

Conservatives have acted to reduce the federal government's role and power by: shifting resources and authority to local and state governments; consolidating programmes, reducing federal regulations and giving local and state governments broad discretion in how they run the programmes; reducing federal safeguards for citizen participation, including public hearings, planning and evaluation requirements; slashing application and reporting requirements so it is impossible to evaluate what is proposed, how the funds have been used and the extent to which these patterns respond to community needs; and cutting the monitoring and enforcement staff of federal agencies to reduce oversight. Legal Services attorneys faced cuts in their budgets and in their freedom to file class actions on controversial issues. The 'war on poverty' became a programme providing services rather than 
supporting development of strong grassroots organisations to represent poor people's interests on controversial issues. Federal programmes providing volunteers and staff to community groups were targets for conservatives who succeeded in eliminating many and severely restricting others.

In short, in 35 years, government policies have systematically reduced political space for lowincome people, making it more difficult for them to intervene effectively to influence decision making by government.

\section{Creating "popular space" through community organising}

Finding less and less political space for influencing key policies, an increasing number of low-income people have decided to create their own space within which they can build their power to change their communities and influence broader policy issues. To make American democracy work better, they have organised thousands of grassroots organisations outside the political realm and then used those organisations to represent their interests and press government and the private sector to open up their decision-making processes, create "popular spaces" and "spaces" and give serious attention to the voices and needs of low-income communities.

Most of the new grassroots groups have developed spontaneously when neighbours have come together out of concern about a community issue and decided to take joint action. Some have begun at the city block level and remained focused on relatively small concerns. Others have grown to represent an entire neighbourhood or rural community. And still others are coalitions of smaller groups which work together on citywide, metropolitan or even state-wide and national issues. These organisations have developed with little encouragement or support from any level of government. In fact, they often have found government officials nervous about their growth, fearing they might become powerful and independent and might generate new leaders who could become their political rivals. Nevertheless, despite this adverse political environment, there has been an enormous growth in the number, sophistication and influence of grassroots groups.

Several developments have led to great gains in the sophistication and strength of this "community organising" in the USA. First, hundreds of people have become skilled community organisers as they have organised people house by house, church by church, issue by issue. These organisers have learned which techniques are most effective in bringing large numbers of people together to work on common issues and in creating political space where they can influence politicians and government officials. They have gradually spread those lessons, expanding the number of organised communities. ${ }^{2}$

Second, an increasing number of grassroots groups have become familiar with effective community organising techniques which trial, error and experience have shown to be particularly successful in organising from the bottom up. ${ }^{3}$ These techniques include:

- 'One on ones': going door to door to interview people about the issues which concern them, their interest in working with others on those issues and their willingness to assume leadership responsibilities.

- Issue campaigns: using these interviews and meetings to identify the issues which most motivate people and then bringing them together to analyse how they might begin addressing the issues, starting with 'immediate and winnable' goals and then using small initial victories to build a growing constituency for bigger issues.

- 'Power analysis': helping community leaders analyse the power situation they face as they seek change by identifying opponents and potential allies, analysing how decisions are made and how they can be influenced and then strategising on building sufficient power to win.

- Leadership development: using each step to give people an opportunity to assume leadership responsibilities, including experience in speaking publicly, running meetings, researching issues, planning campaigns and actions and making demands; being disciplined in using these experiences to test and train leaders, helping them reflect on their own performance and assess what they have learned; helping the most effective leaders move up to take on more responsibility.

This series of techniques has greatly increased the skills and power of poor people and minorities as they have fought for greater influence on government policies and private sector institutions. The grassroots groups which are being built are 
increasingly important vehicles for revitalising democracy, as they give ordinary people an opportunity to become far more engaged in civic life and far better equipped to represent their own interests on issues which are vital to them and their communities.

Third, training schools and 'organising networks' are speeding up the organising of additional communities. They provide new organisers with training on-the-job, classroom sessions and personal mentoring. Some provide already trained people to staff community organisations, giving them access to far more experienced staff than they could find locally and backing them up with continuing supervision and training. Networks also provide continuing training, peer learning and peer support, ensuring they are constantly honing their skills and being exposed to new issues and strategies.

\section{Influencing "their space" through larger campaigns}

In addition, organising networks and support organisations like the Center for Community Change help with replication of successful issue campaigns so groups can intervene effectively in the political space which exists while also working to open up and expand that space. These support groups inform organisers and community leaders about how other communities have tackled similar issues, spreading campaigns from community to community. In the US, for example, organising networks have helped groups in dozens of communities persuade local and state governments to enact laws setting a "living wage" for all jobs created on government-funded projects or related to government purchases of goods and services from the private sector. Furthermore, support organisations have helped grassroots groups create coalitions to conduct state-wide and national issue campaigns. This is a very significant development, as many of the most important issues facing lowincome people are determined by state and national policies, which are decided at a great distance from local grassroots groups. ${ }^{4}$

The National Campaign for Jobs and Income Support systematically worked to develop new ways to help local groups have an impact on distant national policy decisions. ${ }^{5}$ The Campaign recognised how difficult it is for grassroots groups to concentrate on national issues when they face so many immediate issues locally and feel powerless to influence large, far away agencies. The National Campaign therefore developed unusual techniques to bring local organising and national advocacy together, such as 'lift campaigns' to lift up issues on which people are organising locally and help them win these issues locally while also moving them to the national level. The National Campaign brought together local campaign leaders, helped them learn from each other so they could enhance their local organising and had them develop a strategy to gain national reforms in ways which fortified rather than weakened their local campaigns.

\section{Increasing influence through citizen monitoring}

Citizen monitoring has proven to be a particularly effective way of increasing a community's ability to influence policy. ${ }^{6}$ It is a form of participatory action research which fortifies community organising and leadership development by involving people from a low-income community directly in researching a key policy or programme. ${ }^{7}$ With help from researchers, residents develop a research design for assessing how a policy is being implemented, whether officials are obeying the law and how well it is meeting community needs. They also conduct a power analysis to identify the different decision makers, their points of view, who are potential allies and how the community might best influence key decisions.

Residents emerge from the monitoring process with an impressive understanding of the political space in which they will be operating, the politics they face and the most promising strategies for bringing about change. Armed with data, they can speak with authority and with facts to back up their positions. They are, in short, well prepared to tackle an issue in a public arena and win. And, through this action, they are being trained as leaders and active participants in strengthening American democracy by increasing the responsiveness and accountability of government and private sector institutions.

There are many examples of the impact of citizen monitoring. One recent example comes from the conservative, largely rural state of Idaho where a local group's citizen monitoring had a remarkable impact on health care policy. The organisation learned from its members that many had found it extremely difficult to enrol in Medicaid, a programme of health insurance for low-income people, despite their eligibility. Few were told about the programme 
and those who tried to enrol found many obstacles blocking them. The group therefore decided to organise a campaign to challenge and change the way the state was administering the programme. Idaho Community Action Network (ICAN) identified 26 people who were eligible for Medicaid and involved them in a simple research effort on Medicaid. The group encouraged them to apply and worked with them to test and document how they were treated during the application process.

The result of this "testing" project was a dramatic example of how a grassroots group can work within its "own space" to master an issue and develop a strategy for exerting great influence in what would normally be a very limited public "space". Using the facts gathered through this monitoring process and the power the group marshalled by organising a mass membership and allies, the organisation went to public officials and the media with evidence of serious problems with how the state was administering the programme. This combination of organising and monitoring enabled the group to expand the space for influence and the results were impressive: there were 17 changes in state policy, including new measures to publicise the programme, a dramatically shortened application process and changes in the hours the offices were open. Enrolment increased substantially as a result of these reforms and the organisation's membership and influence grew as a result of these successes. ${ }^{8}$

A similar testing approach has led to dramatic gains on another important issue: access to job training. The Anti-Displacement Project (ADP) in Springfield, Massachusetts involved 42 low-income people in testing how well the local employment and training agency was meeting the needs of people who applied for assistance. The bottom line from this citizen monitoring? Of the 42 people who applied for assistance, not a single one was referred for job training. ADP then used the data to document a series of serious problems and went to city decision makers armed with this information.

ADP members backed up these talks with protest rallies, creating new, not officially sanctioned 'space' in which to gain press attention and public backing. They succeeded in convincing city officials to replace the private for profit agency which had the contract to administer the Workforce Investment Programme locally. Its replacement was a non-profit organisation, which was far more committed to providing the training and services which ADP's members needed and far more responsive to the needs and priorities of the people it served.

\section{Combining citizen monitoring and organising on national policies}

As the US government has shifted more federal programmes to the state and local level, community groups have been forced to develop new ways of increasing their influence on state and local government decisions. In some cases the federal government created some political space for grassroots involvement. Citizen monitoring is an excellent approach for helping local groups tie into larger national efforts to influence federal policy. The National Citizens' Monitoring Project on Community Development Block Grants (CDBG) was a particularly ambitious and successful initiative which married local organising and citizen monitoring with a national policy campaign. ${ }^{9}$ The CDBG made provision for a public hearing (but did not require that it be held at convenient times, or in convenient locations, or that officials pay much attention to what they heard) and required quite detailed applications and performance reports, but routinely approved them with little review.

A coalition of national organisations created the National Citizens' Monitoring Project to help grassroots groups increase their influence, and the influence of the poor people who were supposed to be the programme's principal beneficiaries, on spending under the Block Grant Programme. They developed a participatory research design which local groups could use to develop a full understanding of the programme and how it was being administered. They provided local groups with funding for staff, training in research techniques and on-site consulting help on research and coalition-building.

Local grassroots leaders took full advantage of the space available to them. They attended hearings, analysed applications and reports, dug through the files and interviewed key decision makers. They immersed themselves in understanding the requirements of federal law, how decisions were being made locally, how money was being spent and the extent to whether any federal laws or requirements were being violated. Special attention was given to assessing whether local officials were complying with the federal requirement that lowincome people be the programme's principal 
IDS Bulletin 35.2 New Democratic Spaces?

\section{Table 1: Using community organising and citizen monitoring to open space and increase} influence

\section{“Our” space $\leftrightarrow$ Interaction $\leftrightarrow$ “Their” space}

"Popular" space for building powerful

outside

organisations separate from policy environment through:

a. Community organising to build the power, of numbers and position

b. Citizen monitoring to build knowledge of issue as well as a "power analysis" which helps in developing effective strategies
"Closed" space with no opportunity for influence
"Invited" space with appearance of openness but little opportunity for influence

New "created" space which results from community pressure

Expanded "popular" space

\section{Community strategies to fully use} and expand space

1. Reveal closed process and demystify it and

2. Discredit it for being closed, or

3. Open it up
1. Dominate it with numbers and knowledge 2. Use it to develop coalition partners and allies on inside

3. Use legal handles to fortify outside group's

4. Change ground-rules to open process and increase influence

1. Create space by opening up access to information

2. Create new spaces with open process, real opportunity

3. Gain formal power for community to veto, approve, modify, or otherwise influence policy or programme

Maintain and continue increasing capacity to use streets, media, courts, politics to influence decisions by expanding support for community organising, monitoring and related legal, communications and policy strategies outside of the formal political space beneficiaries. And the community groups' interviews helped them discover potential allies inside and outside government as they developed coalitions and informal alliances to increase their influence.

Over 80 communities participated in this project. Each produced annual reports on the programme and used those facts to push for programme improvements. Many illegal projects were eliminated and virtually every monitoring group made substantial gains. In Philadelphia, for example, armed with information gained through monitoring, a tenantled coalition convinced the city council to override the mayor and require that 60 per cent of the funds be spent on improving low-income housing. ${ }^{10}$ Perhaps most significantly, large numbers of community people greatly increased their knowledge and their leadership skills and dozens of community groups moved to a new level of influence because of their experience in this research, analysis, organising and coalitionbuilding process. At the national level, staff developed national reports that drew from the local research. They involved local leaders in the analysis and developing recommendations for national policy change. These recommendations then became the platform the local groups and their national allies used in advocating for further reforms in the programme. In addition to increased targeting to benefit low-income people, these victories included several measures designed specifically to create new "space" for citizen involvement; more public hearings, stricter citizen participation standards and tougher federal oversight and enforcement. 
These national and local victories demonstrate how citizen monitoring can combine participatory research, local organising and national advocacy to increase the voice and power of low-income people and minorities in "their space", the forums which seldom provide marginalised people with a real opportunity to have an impact.

\section{Both/and: the need to expand both "our space" and "their space"}

Grassroots groups in the USA have given little attention to the potential of focusing systematically on broad new campaigns to revitalise democracy by opening up officially sanctioned opportunities for low-income people and others to influence policy. Activists and organisers have concentrated far more on building community groups and coalitions and trying to influence government agencies and corporations from the outside than on seeking far-reaching measures to increase the transparency of major institutions and mandate more open and democratic decision-making processes.

This focus on working in "our space" to create independent voices and power has been a wise and necessary response to an increasingly conservative era. It has resulted in significant victories in creating new space and opportunities for influence, but those victories have been episodic. It is time, however, for community leaders and their allies to focus again on what they might gain from giving new attention to pressing for officially sanctioned measures to open up decision making and increase transparency so that grassroots groups can have more influence on critical issues. Those measures could include:

- New mandates giving citizens access to vital information, the sine qua non to informed citizen action inside or outside the official processes.

- New measures to use technology to broaden access to and analyse data on critical issues.

- New requirements for public notice, public hearings and other government procedures which encourage participation.

- Participatory evaluations of government and private sector programmes involving low-income people and other stakeholders.
- Increased monitoring, evaluation and oversight by the legislative branches of government (which are frequently more accessible to public input than executive agencies).

At the same time it is essential that social change agents work together to expand support for the critical work of community organising, coalition-building and citizen monitoring outside official channels, where independent democratically controlled organisations can involve ordinary people in studying issues and learning to be leaders who can influence major institutions on the issues which matter most to them. This support must include funding for their core operations as well as their monitoring and other programmatic work. It must also include measures to increase their access to help from peers, networks, helpful evaluators and learning partners and support organisations, which can greatly enhance their ability to make rapid progress.

\section{Conclusion}

In the USA, politics is heavily dominated by the large middle-class and strong economic interests. As a relatively small minority, poor people thus face particular challenges in influencing important policy decisions. They have neither the numbers nor the wealth to have easy access to decision makers and there is little officially sanctioned "space" and opportunity for them to have an influence. However, in many communities, local leaders have developed powerful organisations, which are having a significant impact on policies. They are doing this through a combination of increasingly skilful community organising, coalition building and citizen monitoring, a combination of approaches which gives them the power and knowledge which are essential if they are to claim and expand political space and to win on issues which are vital to their communities. These grassroots efforts and parallel efforts to make government agencies and private sector institutions more transparent and accountable, deserve strong support as essential steps toward revitalising American democracy. 
IDS Bulletin 35.2 New Democratic Spaces?

\section{Notes}

1. Throughout this article, "our space" and "popular space" are used interchangeably.

2. For more information on community organising in the USA, see Wood (2002) and Osterman (2003).

3. For more details on these and other techniques used in the USA, see Bobo et al. (2001).

4. An early example of dramatic grassroots success at the national level was the passage of two pieces of federal legislation on banking issues. Community groups, which were very concerned that banks were refusing to invest in their neighbourhoods and that this led to a decline in jobs and in housing conditions, pressed local banks to invest more heavily in their communities. Although there were some local victories, it quickly became apparent that grassroots groups had neither the information about investment patterns nor the political space they needed to have a major influence on investment practices. Community groups in Chicago called a national conference and over 1,000 groups came together and agreed to push for federal legislation requiring that banks disclose where they were investing their funds. A long campaign in which local groups put pressure on their local Congressmen and Senators led to the enactment of the Home Mortgage Disclosure Act, which provided grassroots groups and others with the information they needed to judge the lending performance of each financial institution. The Disclosure Act required federally regulated institutions to disclose, each year, which communities they invested their funds in. The grassroots coalition then

\section{References}

Bobo, K., Kendall, J. and Max, S., 2001, Organizing for Social Change: Midwest Academy Manual for Activists, Washington, D.C.: Seven Lock Press

Osterman, P., 2003, Gathering Power: The Future of Progressive Politics in America, Boston: Beacon Press won passage of the Community Reinvestment Act, which created new "political space" on banking issues: it enabled a community group to challenge a bank for not meeting the credit needs of its lower income community. With this combination of access to critical information and an opportunity to challenge existing practices and even to block the expansion of banks which could not meet the test, community groups had the power to negotiate for the reinvestment of hundreds of billions of dollars of private investment. This has made an enormous difference in many American communities.

5. A national coalition of over 1,000 community groups and staffed by the Center for Community Change.

6. Many other terms are used to describe this activity, including Participatory Action Research.

7. For more on US experience with citizen monitoring, see Parachini and Mott (2002).

8. Based on this success, the National Campaign for Jobs and Income Support worked with groups in several other states to replicate this "citizen monitoring" approach. Furthermore, the National Campaign developed a national report (entitled Access Denied), summarising its findings at these different sites and involved the community groups who had gathered those facts in a national effort which succeeded in convincing federal officials to toughen their oversight of the programme so that more people would receive the health insurance to which they were entitled.

9. See Parachini and Mott (2002).

10. See Parachini and Mott (2002: 15).

Parachini, L. and Mott, A., 2002, 'Strengthening community voices in policy reform', unpublished, available through author: andy.mott@aspeninst.org (unpublished paper)

Wood, R., 2002, Faith in Action: Religion, Race and Democratic Organizing in America, Chicago: University of Chicago Press 